\title{
The Role of School Counsellors and Psychologists in Supporting Transgender People
}

\author{
Damien W. Riggs and Clare Bartholomaeus \\ School of Social and Policy Studies, Flinders University, Adelaide, Australia
}

\begin{abstract}
As growing numbers of transgender people — including students, parents, and educators - become visible within schools, so comes with this the requirement that schools ensure their full inclusion. This article suggests that school counsellors and psychologists have an important role to play in supporting transgender people within schools. As an initial scoping of this suggestion, the article reports on findings from two Australian surveys: one focused on cisgender parents of transgender children, and one focused on cisgender school counsellors and psychologists in regard to their capacity for working with transgender people. The findings suggest that while the parent sample had largely negative experiences with school counsellors, the professional sample reported a high level of confidence in working with transgender people, although differences in gender and religiosity impacted upon school counsellors' and psychologists' acceptance of transgender people, and clinical knowledge for working with transgender people. The article concludes by advocating for ongoing training for school counsellors and psychologists in regard to working with transgender people, in addition to outlining the role that school counsellors and psychologists can play in facilitating a whole of school approach to transgender issues.
\end{abstract}

Keywords: transgender, counselling, schools, inclusive education

Anecdotal evidence widely reported in the Australian news media over the past 2 years indicates that a rapidly growing number of school children are disclosing a transgender identity (e.g., Balakumar, 2014; Preiss, 2015). Furthermore, research evidence indicates that increasing numbers of Australian transgender adults are becoming parents (Riggs, Power, \& von Doussa, in press). This increase in both the numbers of transgender children and parents would suggest that Australian schools are increasingly likely to have transgender people within their school community, thus signalling the importance of educational policies and practices that recognise the specific needs of transgender people. School counsellors and psychologists may have a particularly important role to play in ensuring the full inclusion of transgender people within educational contexts (House \& Hayes, 2002; Ratts, DeKruyf, \& Chen-Hayes, 2007; Singh, Urbano, Haston, \& McMahon, 2010).

Received 6 October 2015; Accepted 24 November 2015

Address for correspondence: Damien W. Riggs, School of Social and Policy Studies, Flinders University, GPO Box 2100, Adelaide SA 5001, Australia. Email: damien.riggs@flinders.edu.au. 
In order to provide an initial scoping of the capacity of Australian school counsellors and psychologists to support the inclusion of transgender people in educational contexts, the present article reports on findings from two surveys that explored the relationship between education, school counsellors and psychologists, and transgender people. The first study surveyed the experiences of 60 Australian parents of transgender children, and the findings reported in this article focus specifically on responses to open-ended questions pertaining to parents' perceptions of their transgender child's experiences with school counsellors. The second study involved a survey of 304 Australian mental health professionals and focused on competencies for working with transgender clients. In this article, findings are reported from the subsample of 28 participants who worked as either qualified counsellors or psychologists in school settings.

Before reporting on these findings, we first briefly outline three interrelated fields of research in regard to transgender people and education, namely: (1) the educational experiences of young transgender people, (2) the education-related experiences of cisgender parents of transgender children, and (3) the capacity of school counsellors and psychologists for supporting young transgender people and their families. The article concludes with recommendations for the continued upskilling of school counsellors and psychologists in working with transgender people, with a particular focus on the role that school counsellors and psychologists can play in facilitating a whole of school approach to transgender issues.

\section{Previous Research}

\section{Educational Experiences of Transgender Young People}

Previous research suggests that the educational experiences of transgender young people are often negative, with transgender students experiencing high levels of harassment, violence, and threats to safety, the correlates of these being higher rates of suicidality among transgender students as compared to their cisgender peers. Greytak, Kosciw, and Diaz, (2009), for example, report that $64 \%$ of the 295 U.S. transgender students they surveyed felt unsafe at school due to fears of discrimination. Several studies in both the United States and Australia have indicated that such fears are well founded, with transgender students reporting high levels of verbal harassment at school from other students (and occasionally school staff), in addition to physical harassment from other students (Goldblum et al., 2012; Greytak et al., 2009; Jones \& Hillier, 2013; Jones et al., 2015; McGuire et al., 2010; Smith et al., 2014; Wyss, 2004). School climate may thus have a significant negative impact upon transgender students' experiences of schooling, with one U.S. study finding that almost half (46\%) of the transgender students surveyed were absent from school in the past month because they felt unsafe or uncomfortable (Greytak et al., 2009).

In regard to the role of school counsellors and psychologists, Australian research by Smith et al. (2014) suggests that of their sample of 189 transgender and gender diverse young people, only 39\% felt that their school provided inclusive counselling services, with $32 \%$ reporting that the counselling provided was inappropriate to their needs. Other Australian research by Jones and Hillier (2013) found that 57\% of 91 transspectrum students surveyed had disclosed their gender identity to a school counsellor, and that of those who had disclosed $74 \%$ felt that they were supported by the school counsellor. 


\section{School-Related Experiences of Parents of Transgender Young People}

Existing small-scale studies have found that a lack of knowledge about transgender issues among school staff makes educational experiences difficult for both parents and children (Pullen Sansfaçon, Robichaud, \& Dumais-Michaud, 2015), and that parents have, at times, experienced hostility (Kuvalanka, Weiner, \& Mahan, 2014). Studies have also shown that relationships between families with transgender young people and school staff are not static. For example, one U.S. study found that although some families had initially positive experiences with school administration, constant challenges in regard to school responses to the young person's gender identity caused administrative resistance and burnout (Johnson, Sikorski, Savage, \& Woitaszewski, 2014). Another U.S. study found that one mother experienced conflicting messages from the school, including initial uncertainty, then a degree of acceptance, then ongoing negative requirements (such as her child having to use the nurse's bathroom rather than the girls' bathroom). In some cases, negative school-related experiences have led to parents removing their children from a school (Johnson et al., 2014; Kuvalanka et al., 2014).

Pullen Sansfaçon et al. (2015) argue that a key barrier to the inclusion of transgender students and their parents in schools relates to how school staff understand gender identity, and specifically whether transgender issues are viewed as taboo topics or whether they are positively included within school polices and practices. A U.S. study confirms this suggestion in the finding that educational systems are more likely to be supportive of families when they have anti-bullying policies that specifically include LGBT students (Johnson et al., 2014).

\section{School Counsellor and Psychologist Competencies}

A small number of existing studies have focused on school counsellor and psychologist competencies for working with transgender students. In the United States, the National Association of School Psychologists (NASP) has a position statement related to transgender and gender diverse students (NASP, 2014); however, it is acknowledged that most school psychologists will typically have received minimal or no training in working with young transgender people (Walzer, 2015). In order to assess the capacity of U.S. school psychologists for working with transgender students, Walzer (2015) designed the Knowledge of and Attitudes Toward Transgender Students Survey (KATTSS), which was then completed by 121 school psychologists. Walzer found that respondents familiar with the NASP position statement on transgender students had a significantly higher score on the KATTSS.

Bowers et al.'s (2015) survey of 246 school psychologists in the United States reported overall highly positive attitudes towards trans students, with $83.7 \%$ of respondents willing/very willing to address the needs of transgender students in schools. Bowers et al. found that comfort addressing the needs of transgender students related to experience working with such students, and that positive attitudes related to a willingness to undertake additional training about transgender issues and the needs of transgender clients. The findings of Bowers et al. indicated that female respondents were more likely to have positive attitudes towards transgender students than were male respondents. 


\section{Method}

Procedure

Both of the studies reported in this article were approved by the ethics board of the authors' institution. Data for the first study were collected via an online survey administered through Survey Monkey. Participants were parents who self-identified as raising at least one transgender child, and were sourced via the first author's existing networks and snowball sampling (such as through email lists and social media sites).

Data for the second study were also collected via an online survey administered through Survey Monkey. Promotion of the survey targeted Australian mental health professionals in general, and advertisements were placed in the Australian Psychological Society's InPsych Bulletin, the Australian Counselling Association's eNewsletter, the Australian Medical Association's Australian Medicine, the Australian Association of Social Workers' E-Bulletin, and the Australian College of Mental Health Nurses' eNewsletter.

\section{Participants}

Sixty heterosexual cisgender parents participated in the first study. The majority $(90.5 \%)$ of participants identified as female. The majority of participants were in heterosexual relationships $(90.5 \%)$, with the remainder stating that they were not currently in a relationship (9.5\%). In terms of state of residence within Australia, 21 participants lived in Queensland, 15 in Victoria, 15 in New South Wales, 9 in South Australia, and 3 in Tasmania. The average number of children within each family was $2.5(S D=1.05)$. Each participant only had one transgender child.

In regard to the second study, a total of 304 Australian mental health professionals completed the survey. Of these, 28 indicated that they worked in school settings, as either qualified counsellors $(n=16)$ or psychologists $(n=12)$. Of this subsample from the wider survey sample, 17 were female and 11 male. All identified as cisgender and heterosexual. The average age of participants in this subsample was 38.43 ( $S D=$ $12.23)$. Eleven of the 28 participants $(39.43 \%)$ had previously worked with a transgender young person as a client. Seven of the 28 participants $(25 \%)$ had previously undertaken training specific to working with transgender people. There were no statistically significant differences between counsellors and psychologists in terms of any of the outcome measures, hence for the purposes of the analysis below, the two professions are treated as one group, given their shared practice context (i.e., schools).

\section{Measures}

The first study utilised a survey designed by the authors of that study (Riggs \& Due, 2013), including both quantitative measures and open-ended questions. Of interest to the present article are responses to two open-ended questions, which asked: (1) 'Please tell us about any experiences you or your transgender child have had with mental health care professionals', and (2) 'Please provide us with some information about the support you and your child have received from your child's school'.

The second study included a range of questions about individual demographics (age, gender, degree of religiosity) and experience, in addition to two standardised measures and one measure designed by the authors. The first of these was an adapted version of the Attitudes Towards Transgender Individuals Scale (ATTIS; Walch, Ngamake, Francisco, Stitt, \& Shingler, 2012), which uses a 5-point Likert scale to assess 
TABLE 1

Items Comprising Acceptance Factor

\begin{tabular}{lr}
\hline Item & Loading \\
\hline 1. Transgenderism should be accepted within society. & .880 \\
2. Transgender people should not be allowed in public spaces. & -.780 \\
3. I avoid transgender people whenever possible. & -.820 \\
4. Transgender people are a valued part of society. & .850 \\
5. Transgender people should not be allowed to present as their preferred gender in public. & -.890 \\
6. There should be no restrictions on transgender people. & .910 \\
7. I would feel comfortable working closely with a transgender person. & .856 \\
8. I would enjoy attending social functions at which transgender people were present. & .832 \\
9. I would be accepting if I learned that my neighbour was a transgender person. & .775 \\
10. I avoid transgender people whenever possible. & -.922 \\
11. I would be happy to have friends who are transgender. & .864 \\
12. I would accept my best friend if they were transgender. & .939 \\
\hline
\end{tabular}

responses to 20 items. When applied to the subsample of 28 participants, the ATTIS did not produce statistically significant findings. In order to determine if aspects of the measure were useful for the present article, a factor analysis was conducted using a Varimax (orthogonal) rotation. A four-factor solution was identified; however, only the first factor presented a logically coherent set of items (accounting for $47.9 \%$ of the variance). The 12 items in this factor, and their loadings, are outlined in Table 1. This factor, referred to as 'acceptance of transgender people' in the analysis below, displayed high reliability, $\alpha=.91$. Higher scores on the measure indicated higher levels of acceptance. The possible range for acceptance scores was 12-60.

The second measure utilised was an adapted version of the Counselor Attitude Toward Transgender Scale (CATTS; Rehbein, 2012), which uses a 10-point Likert scale to assess responses to 20 items. Again, when applied to the subsample, the CATTS did not produce statistically significant findings. A factor analysis using a Varimax (orthogonal) rotation was again undertaken. A three-factor solution was identified; however, again only the first factor presented a logically coherent set of items (accounting for $56.3 \%$ of the variance). The six items in this factor, and their loadings, are outlined in Table 2. This factor - referred to in the analysis below as 'clinical knowledge' - displayed high reliability, $\alpha=.89$. Higher scores on the measure indicate higher levels of accurate clinical knowledge about transgender clients as determined by current guidelines for mental health practice with transgender people (e.g., Association for Lesbian, Gay, Bisexual, and Transgender Issues in Counseling, 2009). The possible range for clinical knowledge scores was 6-60.

A third measure was used to assess confidence in working with trans clients. Designed by the authors, this measure - the Confidence in Working with Transgender Clients Measure - included six items assessed via a 5-point Likert scale. Each of the six items assessed confidence in working in a different area related to transgender clients: with adults, children, adolescents, parents, partners, and extended family and friends. For example, 'I feel confident in providing a mental health service to young transgender people. The measure displayed high reliability, $\alpha=.97$. Higher scores on the measure indicate higher levels of confidence. The possible range for confidence was 6-30. 
TABLE 2

Items Comprising Clinical Knowledge Factor

\begin{tabular}{lr}
\hline Item & Loading \\
\hline $\begin{array}{l}\text { 1. Mental health professionals always know more about transgenderism than do } \\
\text { transgender people. }\end{array}$ & -.842 \\
2. Transgender clients' presenting issues always centre around or are linked to their & -.790 \\
gender expression. & -.951 \\
3. All transgender clients should be diagnosed with gender dysphoria. & .942 \\
4. All mental health professionals should receive mandatory training in working with & -.855 \\
transgender people. & \\
5. As a mental health professional it is my role to determine whether or not a person is & -.940 \\
transgender. & \\
6. Using an incorrect pronoun when working with a transgender client is an acceptable & \\
mistake. &
\end{tabular}

\section{Analytic Approach}

In regard to the first study, all responses to the two questions outlined above that made direct reference to school counsellors were extracted from the data set. A total of nine participants (15\%) provided responses that mentioned school counsellors. A conventional content analysis (Hsieh \& Shannon, 2005) of these responses indicated that the responses were clearly divided into two groups: negative accounts of school counsellors $(n=6)$ and positive accounts of school counsellors $(n=3)$. All nine responses are included in the results below with comment made on specific features indicating what constituted either negative or positive accounts.

In regard to the second study, data were exported from SurveyMonkey into SPSS 21.0. The data were cleaned in two specific ways. First, negatively scored items on the two scales were reversed. Second, composite scores were generated for the scales outlined above. Given the relatively small sample size $(n=28)$, the data were examined to ensure the appropriateness of utilising statistical testing. Cohen's $d$ was calculated for all $t$ tests, and Cohen's $f^{2}$ was calculated for the regression. All of these tests, reported below, indicated very large effect sizes. These effect sizes were then used to determine whether the tests were sufficiently powered to warrant rejection of the null hypothesis. Post hoc calculations based on effect and sample size indicated that both the $t$ tests and regression far exceeded Cohen's (1988) minimum recommendation of .80 .

\section{Results}

\section{Experiences of Parents of Transgender Children Study}

Six of the participants who reported experiences with school counsellors provided a negative account. Of these, two of the counsellors appeared to have entirely discounted the possibility of a child being transgender:

The school counsellor told me it wasn't possible for a child to be transgender. They tried to say that maybe my child was intersex, but then said they didn't have time to research it and instead told me to see a paediatrician who refused to see us because they had no knowledge. (Mother of 12-year-old transgender son, Queensland) 
The school counsellor was very judgmental, critical and prejudiced. He told my son that he wasn't trans but just afraid of puberty. When I went in to speak with the counsellor he made it out like I was to blame for my son's gender questioning. (Mother of 16-year-old transgender son, Queensland)

A further two counsellors appeared to suggest that a child's transgender expression should be responded to with behaviour management techniques aimed at altering their gender expression:

The only bad experience we had was with the school counsellor in my child's first year at school. She said that I had to take away all the boys clothes, force my child into girls' clothes, 'Nip it in the bud now'. I explained that I believed this would do more harm than good and would likely scar my child for life. I said that changing clothes was not going to stop my child being transgender. (Mother of 12-year-old transgender son, Victoria)

At first we thought the school counsellor was an asset, but we then learnt that they had suggested to the Principal that our child was just trying to get attention, and that what was needed was behaviour management, not affirmation of her gender. (Mother of 14-year-old transgender daughter, South Australia)

One of the negative accounts of school counsellors emphasised a general lack of knowledge:

The school in general don't know about her gender variance. The school counsellor in particular, who I would have thought should know better, seemed to have no knowledge at all about transgender issues, and was no use at all. (Mother of 16-year-old transgender daughter, New South Wales)

The final negative account reported an instance of a counsellor failing to display discretion with regard to the personal information of a transgender student:

We recently withdrew our daughter from school. She was in high school anonymously in that only the immediate staff knew about it, including the school counsellor. Or so we thought. Turned out that the counsellor had disclosed to seven other staff members without our consent because they thought they 'needed to know'. This then led to some of these teachers mentioning it to students, which resulted in our child being in class one morning when a child stated 'apparently a transgender kid goes to this school and IT is using the wrong toilets'. (Mother of 13-year-old transgender daughter, South Australia)

The negative experiences reported by participants mirror previous research documenting adult transgender people's experiences in two ways: (1) a general lack of knowledge, and (2) specific instances of transphobic responses by counsellors (Riggs, Coleman, \& Due, 2014).

What was lacking when it came to negative experiences was what, it would appear, constituted positive experiences for the three participants who spoke positively about school counsellors:

The school in general don't seem to have any understanding of gender variance. However, the school counsellor has been helpful. They pointed me in the direction of the Royal Children's Hospital in order to get medical and psychiatric support. (Mother of 17-year-old transgender son, Victoria)

The school counsellor has been very supportive of our child and has definitely played a very important role for them at the school in terms of accessing resources, however the school 
more widely is not yet aware of things so we are hoping that the counsellor can provide support when that happens. (Mother of 14-year-old transgender son, Victoria)

Initially the stand-out positive was just to be heard without feeling judged, specifically by the school counsellor. Then our focus was on information and guidance, and the school counsellor was able to provide that to us in terms of reading materials and referrals to specialists. (Mother of 12-year-old transgender daughter, New South Wales)

The positive accounts provided by participants again highlight what is elsewhere documented in research with transgender adults, namely that mental health professionals who are affirming, informed, and able to provide access to resources are experienced positively (Riggs et al., 2014).

It is important to note that while the nine participants who provided responses referred to 'school counsellors', it is not possible to know the actual qualifications of the staff members referred to. Employment criteria for school counsellors or psychologists vary across Australian states and territories (Australian Psychologists and Counsellors in Schools Association, 2013), and thus it may be possible that the professionals referred to were qualified social workers, psychologists, counsellors, or potentially in some contexts, teachers. For the purposes of the analysis we have presented above, however, we have taken at face value the description provided by participants in terms of their perception (and expectations) of the role of the individuals referred to as 'school counsellors'. Given that the nine responses came from participants located across four states, and with almost equal numbers of sons and daughters, it is reasonable to suggest that the experiences reported here are at least some degree reflective of both parent and child experiences, regardless of the actual qualifications of those viewed as school counsellors.

Acceptance and Clinical Knowledge Among School Counsellors and Psychologists Study

Across the subsample of 28 participants who worked in school settings, the average score for acceptance was $43.10(S D=2.11)$, indicating that overall the sample was moderately accepting of transgender people. In terms of levels of clinical knowledge, the average score was $48.33(S D=7.65)$, indicating that overall the sample had fairly high levels of clinical knowledge about working with transgender people. Finally, in terms of confidence in working with transgender people, the average score was 27.90 $(S D=2.27)$, indicating that overall the sample was very confident in working with transgender people.

In terms of gender differences among the sample of 28 participants, female participants reported higher levels of accurate clinical knowledge $(M=48.92, S D=$ 8.72) than did male participants $(M=30.20, S D=5.73), t=3.097, p=.02, d=$ 2.53. Similarly, female participants reported higher levels of acceptance of transgender people $(M=43.40, S D=1.93)$ than did male participants $(M=38.35, S D=2.23)$, $t=3.273, p=.03, d=2.42$.

In terms of previous experience in working with transgender people, participants who had previously worked with a young transgender person reported more confidence in working with transgender people $(M=28.15, S D=2.24)$ than did people who had not previously worked with a transgender person $(M=23.50, S D=1.70)$, $t=2.633, p=.03, d=2.33$. 
Three statistically significant correlations were identified between the outcome measures and one of the demographic measures (religiosity, measured on a scale from $1=$ not at all religious to $4=$ very religious). First, there was a strong negative correlation between degree of religiosity and acceptance of transgender people, $r=-.545, p=.01$. More religious participants were less accepting of transgender people. Second, there was a strong positive correlation between acceptance of transgender people and confidence in working with transgender people, $r=.592, p=$ .01. Participants who were more accepting were more confident. Third, there was a strong positive correlation between accurate clinical knowledge about working with transgender people and confidence in working with transgender people, $r=-.609$, $p=.01$. Participants who had higher levels of accurate clinical knowledge were more confident.

Given the relationships between the variables as outlined above, a simultaneous multiple regression was conducted utilising confidence as the outcome variable, and gender, religiosity, experience in working with transgender people, acceptance, and clinical knowledge as predictor variables. The model predicted $65.7 \%$ of the variance $\left(R^{2}=.657, F(5,28)=6.739, p=.03, f^{2}=2.00\right)$. Of the predictor variables, gender contributed the largest proportion of unique variance $(\beta=.613, p=.01)$, followed by religiosity $(\beta=.485, p=.01)$, acceptance $(\beta=.221, p=.03)$, clinical knowledge $(\beta=.217, p=.03)$, and experience in working with transgender people $(\beta=.128$, $p=.04)$.

\section{Discussion}

The findings reported above largely mirror previous research on both the experiences of adult transgender people who access mental health services, and the competencies of mental health professionals. Specifically, the findings indicate that parents and their transgender children who access school counsellors perceive a general lack of knowledge and support from counsellors, echoing the findings of Pullen Sansfaçon et al. (2015). In terms of school counsellors and psychologists themselves, while the sample reported relatively high levels of accurate clinical knowledge and confidence, and moderate levels of acceptance, differences in terms of the impact of gender and religiosity specifically appear to suggest that these individual differences likely shape the service provided (i.e., male and more religious counsellors and psychologists may be less confident or willing to provide supportive and inclusive services). These findings echo those of Bower et al. (2015), who in general found positive attitudes among their sample of school psychologists, but that female participants were more positive than were male participants.

Despite the relatively high levels of accurate clinical knowledge and confidence among the sample of school counsellors and psychologists, the experiences of the parent participants, along with the fact that counsellors and psychologists reported only moderate levels of acceptance of transgender people, suggest the importance of further training and awareness raising for counsellors and psychologists so as to better ensure the full inclusion of transgender people. This may be especially pertinent in the Australian context, given recent debates about the role of school chaplains in providing counselling services to students (Law \& Stott, 2014). Given religiosity was a predictor of acceptance, it would appear important to continue to examine whether school chaplains may struggle to reconcile their religious beliefs with providing inclusive and 
affirming responses to transgender students. In what follows, after first outlining the limitations of the studies reported, we draw some broader conclusions, specifically considering the importance of ongoing training, in addition to outlining the role that school counsellors and psychologists can play in supporting the inclusion of transgender people in schools.

\section{Limitations}

In terms of limitations, it must be acknowledged that the findings reported in this article draw on two relatively small samples, and that neither study was focused solely on experiences with or of school counsellors or psychologists. Despite this, the large effect sizes and the fact that the statistical tests were more than sufficiently powered would suggest that the findings reported here have some importance. Future research that specifically focuses on the experiences of parents and their transgender children with school counsellors and psychologists, along with research that focuses on the competencies of school counsellors and psychologists to work with transgender young people and their families, is nonetheless warranted. Finally, given the fact that the findings from the second study relied upon factor analysis of existing measures in order to identify statistically significant findings, it is important that the factors identified are further tested in future research.

\section{Conclusion}

As noted above, it would appear important that school counsellors and psychologists undertake ongoing training for working with transgender people. Previous research suggests that such training should address participants' awareness of their own understandings and beliefs about gender and how this may impact on transgender people (Chen-Hayes, 2001; Singh \& Burnes, 2009). Counsellors and psychologists should also be reflective about their own potential discomfort and inexperience in supporting transgender students (Wells \& Tsutsumi, 2005). School counsellors and psychologists may benefit from engaging with broader community organisations such as Safe Schools programs - in order to further their own understanding and to receive support in working with transgender students (Case \& Meier, 2014; Gonzalez \& McNulty, 2010).

Importantly, the presence of transgender people in schools extends beyond transgender students. Schools also have a role to play in ensuring the inclusion of both transgender parents and staff, a role that school counsellors and psychologists may take the lead in. A study of 50 U.S. transgender parents, for example, found that very few were 'out' to officials at their child(ren)'s school, due to concerns about discrimination (Haines, Ajayi, \& Boyd, 2014). Acceptance of transgender parents in the school environment, including by staff, other parents, and students, can be important in supporting children whose parent is transitioning (Hines, 2006). Counsellors and psychologists can assist in making schools safer and more inclusive spaces for transgender parents, specifically through providing training for school staff, advocating for policies promoting inclusion, and broadening the language used to discuss families within school curriculum (Ryan \& Martin, 2000).

In conclusion, the findings presented in this article and the overview provided of both previous research and practice recommendations for supporting the full inclusion of transgender people in schools suggest that school counsellors and psychologists 
have an important role to play. Specifically, the findings reported here suggest the need for whole of school approaches that proactively ensure the inclusion of transgender people, regardless of whether or not a particular school has transgender students, parents, or staff among its population. In other words, ensuring the full inclusion of transgender people in educational contexts requires policies and practices that treat such inclusion as an a priori, rather than premising inclusion on the existence of individual transgender people.

\section{Acknowledgments}

We begin by acknowledging the sovereignty of the Kaurna people, the First Nations people upon whose land we live and work. Thanks must go to helpful comments from the three reviewers and the journal editor, Chris Boyle, in addition to audience feedback provided on an earlier version of the paper presented at the Australian Psychologists and Counsellors in Schools National Conference, 2015. Finally, thanks must go to Clemence Due for her work on the development of the first study reported in this article.

\section{Financial Support}

Funding for the research reported in this article was provided by the Flinders University Faculty of Social and Behavioural Sciences.

\section{Conflicts of Interest}

None.

\section{Ethical Standards}

The authors assert that all procedures contributing to this work comply with the ethical standards of the relevant national and institutional committees on human experimentation and with the Helsinki Declaration of 1975, as revised in 2008.

\section{References}

Association for Lesbian, Gay, Bisexual, and Transgender Issues in Counseling. (2009) Competencies for counseling with transgender clients. Alexandria, VA: Author.

Australian Psychologists and Counsellors in Schools Association. (2013). An Australia wide comparison of school psychologists/counsellors/guidance officers 2013. Retrieved from http://www.agca. com.au/a_docs/APACS_AUSTRALIA_WIDE_COMPARISON_2013.docx

Balakumar, A. (2014, November 18). Isabelle is 11. She's an Australian girl born in a boy's body, and she's telling her story. mamamia. Retrieved from http://www.mamamia.com. au/social/four-corners-transgender-report/

Bowers, S., Lewandowski, J., Savage, T.A., \& Woitaszewski, S.A. (2015). School psychologists' attitudes toward transgender students. Journal of LGBT Youth, 12, 1-18. doi:10.1080/19361653.2014.930370

Case, K.A., \& Meier, S.C. (2014). Developing allies to transgender and gender-nonconforming youth: Training for counselors and educators. Journal of LGBT Youth, 11, 62-82. doi:10.1080/19361653.2014.840764

Chen-Hayes, S.F. (2001). Counseling and advocacy with transgendered and gender-variant persons in schools and families. Journal of Humanistic Counseling, Education and Development, 40, 34-48. doi:10.1002/j.2164-490X.2001.tb00100.x 
Cohen, J. (1988). Statistical power analysis for the behavioural sciences. Mahwah, NJ: Lawrence Erlbaum Associates.

Goldblum, P., Testa, R.J., Pflum, S., Hendricks, M.L., Bradford, J., \& Bongar, B. (2012). The relationship between gender-based victimization and suicide attempts in transgender people. Professional Psychology: Research and Practice, 43, 468-475. doi:10.1037/a0029605

Gonzalez, M., \& McNulty, J. (2010). Achieving competency with transgender youth: School counsellors as collaborative advocates. Journal of LGBT Issues in Counseling, 4, 176-186. doi:10.1080/15538605.2010.524841

Greytak, E.A., Kosciw, J.G., \& Diaz, E.M. (2009). Harsh realities: The experiences of transgender youth in our nation's schools. New York: Gay, Lesbian and Straight Education Network (GLSEN).

Haines, B.A., Ajayi, A.A., \& Boyd, H. (2014). Making trans parents visible: Intersectionality of trans and parenting identities. Feminism \& Psychology, 24, 238-247. doi:10.1177/0959353514526219

Hines, S. (2006). Intimate transitions: Transgender practices of partnering and parenting. Sociology, 40, 353-371. doi:10.1177/0038038506062037

House, R.M., \& Hayes, R.L. (2002). School counsellors: Becoming key players in school reform. Professional School Counseling, 5, 249-256.

Hsieh, H.F., \& Shannon, S.E. (2005). Three approaches to qualitative content analysis. Qualitative Health Research, 15, 1277-1288. doi:10.1177/1049732305276687

Johnson, D., Sikorski, J., Savage, T.A., \& Woitaszewski, S.A. (2014). Parents of youth who identify as transgender: An exploratory study. School Psychology Forum, 8, 56-74.

Jones, T., \& Hillier, L. (2013). Comparing trans-spectrum and same-sex-attracted youth in Australia: Increased risks, increased activisms. Journal of LGBT Youth, 10, 287-307. doi:10.1080/19361653.2013.825197

Jones, T., Smith, E., Ward, R., Dixon, J., Hillier, L., \& Mitchell, A. (2015). School experiences of transgender and gender diverse students in Australia. Sex Education. doi:10.1080/14681811.2015.1080678

Kuvalanka, K.A., Weiner, J.L., \& Mahan, D. (2014). Child, family, and community transformations: Findings from interviews with mothers of transgender girls. Journal of GLBT Family Studies, 10, 354-379. doi:10.1080/1550428X.2013.834529

Law, J., \& Stott, R., (2014). Serious concerns raised about national chaplaincy program as government reaffirms commitment to initiative. news.com.au. Retrieved November 16, 2015, from http://www.news.com.au/national/serious-concerns-raised-about-national-school-chaplaincyprogram-as-government-reaffirms-commitment-to-initiative/story-fncynjr2-1226961285904

McGuire, J.K., Anderson, C.R., Toomey, R.B., \& Russell, S.T. (2010). School climate for transgender youth: A mixed method investigation of student experiences and school responses. Journal of Youth and Adolescence, 39, 1175-1188. doi:10.1007/s10964-010-9540-7

National Association of School Psychologists (NASP). (2014). Position statement: Safe schools for transgender and gender diverse students. Bethesda, MD: Author.

Preiss, B. (2015, May 31). Royal Children's Hospital transgender unit gets $\$ 6 \mathrm{~m}$ boost to cut waiting list. The Age. Retrieved from http://www.theage.com.au/victoria/royal-childrenshospital-transgender-unit-gets-6m-boost-to-cut-waiting-list-20150531-ghdkgd.html

Pullen Sansfaçon, A., Robichaud, M.J., \& Dumais-Michaud, A.A. (2015). The experience of parents who support their children's gender variance. Journal of LGBT Youth, 12, 39-63. doi:10.1080/19361653.2014.935555

Ratts, M.J., DeKruyf, L., \& Chen-Hayes, S.F. (2007). The ACA advocacy competencies: A social justice advocacy framework for professional school counsellors. Professional School Counseling, 11, 90-97.

Rehbein, R.N. (2012). Transition in conceptualizing the transgender experience: A measure of counselor attitudes (Masters thesis). Eastern Illinois University, Charleston, IL.

Riggs, D.W., Power, J., \& von Doussa, H. (in press). Parenting and Australian trans and gender diverse people: An exploratory survey. International Journal of Transgenderism.

Riggs, D.W., Coleman, K., \& Due, C. (2014). Healthcare experiences of gender diverse Australians: A mixed-methods, self-report survey. BMC Public Health, 14, 230-234. doi:10.1186/1471-2458-14-230 
Riggs, D.W., \& Due, C. (2015). Support experiences and attitudes of parents of gender variant children. Journal of Child and Family Studies, 24, 1999-2007. doi:10.1007/s10826-014-9999-z

Ryan, D., \& Martin, A. (2000). Lesbian, gay, bisexual, and transgender parents in the school systems. School Psychology Review, 29, 207-216.

Singh, A.A., \& Burnes, T.R. (2009). Creating developmentally appropriate, safe counseling environments for transgender youth: The critical role of school counsellors. Journal of LGBT Issues in Counseling, 3, 215-234. doi:10.1080/15538600903379457

Singh, A.A., Urbano, A., Haston, M., \& McMahon, E. (2010). School counsellors' strategies for social justice change: A grounded theory of what works in the real world. Professional School Counseling, 13, $135-145$.

Smith, E., Jones, T., Ward, R., Dixon, J., Mitchell, A., \& Hillier, L. (2014). From blues to rainbows: The mental health and well-being of gender diverse and transgender young people in Australia. Melbourne, Australia: Australian Research Centre in Sex, Health and Society (ARCSHS), La Trobe University.

Walch, S.E., Ngamake, S.T., Francisco, J., Stitt, R.L., \& Shingler, K.A. (2012). The Attitudes Toward Transgendered Individuals Scale: Psychometric properties. Archives of Sexual Behavior, 41, 1283-1291. doi:10.1007/s10508-012-9995-6

Walzer, A.J. (2015). School psychologists' knowledge of and attitudes toward transgender students (Master's thesis). Rowan University, Glassboro, NJ.

Wells, K., \& Tsutsumi, L.M. (2005). Creating safe, caring and inclusive schools for LGBTQ students: A guide for counsellors. Alberta, Canada: The Society for Safe and Caring Schools and Communities.

Wyss, S.E. (2004). 'This was my hell': The violence experienced by gender nonconforming youth in U.S. high schools. International Journal of Qualitative Studies in Education, 17, 709-730. doi:10.1080/0951839042000253676 